\title{
Progressive painless lower limbs weakness in a dialyzed patient: undiagnosed tertiary syphilis: a case report
}

\author{
O Dahmani ${ }^{*}$, N Target $^{1}$, JP Guy ${ }^{1}$, S Belkhelfa ${ }^{2}$, F Mermet Jeanvoine ${ }^{3}$, J Servonnat ${ }^{3}$, J Djellid ${ }^{4}$
}

\begin{abstract}
Introduction: Syphilis is a sexually transmitted disease, remaining under-estimated, under-recognized due to the variability of clinical presentation and ageing of the population with chronic comorbidities. Hence, some manifestations of the past are nowadays superimposed on the course of chronic diseases. Clinical suspicion should be guided by past medical history of contracting any other sexual disease in a heterosexual person or man who has sex with man.

Case presentation: We describe a rare case of tertiary syphilis in a hemodialyzed diabetic patient whom was career of chronic liver disease due to the evolution of chronic hepatitis B virus infection complicated by a hepatocellular carcinoma. Initial orientation in diagnosing this rare presentation of progressive painless lower limbs weakness was attributed to possible side effects of ongoing anti viral therapy including lamivudine and adefovir. We continued administering both drugs while patient notified a spectacular improvement under Ceftriaxone therapy introduced empirically for a possible chest infection. Routine ophthalmologic examination realized in a teaching hospital, scheduled without knowing the course of late infection showed the presence of a syphilitic uveitis.

Conclusion: This case emphasizes the need for a high index of clinical suspicion for syphilis before the occurrence of symptoms related to its end organ damage dominated by neurosyphilis form. Early diagnosis is the key to preventing significant morbidity and mortality and improving prognosis. However, in the setting of chronic diseases such as chronic kidney diseases either before setting up methods of renal replacement therapy or under immune-suppressive therapy; clinical presentation might resemble any disease, delaying the certitude of the diagnosis by prescribing a rapid plasma reagin.
\end{abstract}

\section{Introduction}

Syphilis remains a common disease worldwide re-emerging as an important disease in western countries [1,2]. Untreated, during its latent phase; it could resemble any disease and escape from diagnosis unless having a high index of suspicion in a patient who contracted any other sexual transmitted diseases. Little is known about syphilis in dialyzed population. Herein, we report a hemodialyzed patient suffering from a progressive painless lower limbs weakness responding favourably to ceftriaxone therapy given initially for a possible chest infection.

\footnotetext{
* Correspondence: omardahmani@hotmail.com

'Department of nephrology, CH Louis Jaillon Saint-Claude, 39206, France
}

\section{Case presentation}

A 63-year-old married man of Asian ethnicity, on regular haemodialysis three times weekly undergoing diabetic nephropathy for the last two years, was complaining of having walking difficulties for two months. He was known to have chronic hepatitis B liver disease staged Child A with grade I oesophageal varices under anti viral therapy including the combination of lamivudine plus adefovir adjusted to kidney function tests. He also had a history of an operated hepatocellular carcinoma. He had many diabetic degenerative complications (proliferative retinopathy, stented ischemic heart disease, peripheral neuropathy) as well. He started complaining of a symmetrical painful proximal lower limbs weakness attributed initially to lumbar root compression 
according to lumbar CT scan and EMG/NCS findings. The former showed diffuse degenerative changes associated with a disc protrusion at L3-L4 level. The later showed evidence of a pending left external popliteal sciatic nerve without evidence of diffuse symmetrical polyneuropathy. Symptoms were relieved by benign pain killer and gabapentin $300 \mathrm{mg}$ every other day. Three months later he arrived at the emergency department with mild fever, non productive cough, nocturnal sweat and inability to walk. Physical examination revealed an ill looking patient, weighing $63 \mathrm{kgs}$ with blood pressure of $154 / 95 \mathrm{mmHg}$, heart rate $104 \mathrm{bpm}$ regular, temperature $38.2 \mathrm{C}$ and oxygen saturation of $95 \%$. Glasgow score was 15 without meningismus or oto-ocular manifestations. Proprioception was conserved and Babinski, Hoffman and Laseque signs were all negative. The patient had mild walking abnormalities, MSGS at 3/5 and very poor squat test. However, both patellar reflexes were active, and symmetric. He had no pain or peripheral numbness. Cardiovascular examination showed moderate tachycardia without friction rub or murmurs. There were bi-basal crackles mostly on the right side with absence of dullness on percussion and hepatojugular reflux. The peripheral pulse was conserved without acrosyndrom. Skin examination showed pityriasis versicolor-like eruptions mainly on upper limbs and upper thorax. The external genitalia revealed hypochromic vitiligoid spots on the scrotum. He was free of lymphadenopathy. Results of laboratory investigations are shown in tables 1, 2 and 3. Sputum smear for bacterial and mycobacterium, urine $\mathrm{C} / \mathrm{S}$, blood $\mathrm{C} / \mathrm{S}$ (3), Mantoux test, were all negative. $\mathrm{iPTH}=205 \mathrm{ng} / \mathrm{l}(15-65), 1,25(\mathrm{OH})$ D3 $24 \mathrm{pmol} / \mathrm{l}(43-148)$ and $25 \mathrm{OH} \mathrm{D} 3=38 \mathrm{nmol} / \mathrm{l}(75$ - 200) with normal phosphocalcic product. VDRL $=2$, TPHA 1280, FTA abs 100, FTA $-\mathrm{M}<10$ and positive anti -TpN47, TmpA, TpN17 and TpN 15(IgG westernblot). EKG showed no new changes and transthoracic Doppler-echocardiography demonstrated normal left ventricular size and function apart from mild concentric hypertrophy. He had no significant valvulopathy, though a calcified bicuspid aortic valve with mild regurgitation was noted without Aortitis or aneurismal aspects. CXR disclosed an interstitial aspect of both field of the lungs and normal sized mediastinal silhouette. Funduscopic appearance showed beside proliferative retinopathy, a syphilitic uveitis thereafter, discovered incidentally elsewhere. Abdominal and pelvis ultrasound study demonstrated mild splenomegaly and poorly differentiated normal sized kidneys with acquired cystic disease. The patient received an empirical treatment of ceftriaxone $1.5 \mathrm{gr}$ administered post-dialysis with a spectacular response within one week; therapy judged by net improvement of his weakness and return home walking. Ceftriaxone alone was maintained to complete duration of two weeks. Meanwhile, the spouse of the patient was convoked for screening. We learned that she had been receiving prednisolone and sub-cutaneous injection of infliximab weekly for the last six months, and ibuprofen for a relapsing rheumatoid arthritis. Awaited syphilitic serologic testing disclosed normal blood chemistry without inflammation $(\mathrm{CRP}=5 \mathrm{mg} / \mathrm{l}) . \mathrm{VDRL}=2$, TPPA $=$ 2560 FTA abs 200 , FTA-M $20(\mathrm{~N}<10)$. A medical report was sent to her general practitioner for intramuscular Benzathin-penicillin therapy 2.4 Millions units weekly over three consecutive weeks.

\section{Discussion}

The diagnosis of late latent syphilis is very difficult to make because of the diversity and similarity of its clinical presentation $[1,3]$. In fact, Sir William Osler stated that "syphilis simulates every other disease" owing to mixed and atypical forms. Besides having a high index of suspicion; past medical history of exposure to Treponema pallidum, and physical examination along with serologic tests remained paramount for the diagnosis. Cerebrospinal fluid (CSF) may be helpful, though neurosyphilis with normal CSF cell count in a HIV negative subject has been reported [4]. In addition a negative

\section{Table 1 Results of haematology laboratory tests}

\begin{tabular}{|c|c|c|}
\hline Variable & Patient & Normal range \\
\hline Haemoglobin (gr/dl) & 10 & $13-17$ \\
\hline Hematocrit (\%) & 29.8 & $40-54$ \\
\hline White cell count (per $\mathrm{mm}^{3}$ ) & 10000 & $4000-10000$ \\
\hline \multicolumn{3}{|l|}{ Differential count: } \\
\hline Neutrophils & 8500 & \\
\hline Lymphocytes & 760 & \\
\hline Monocytes & 670 & \\
\hline Eosinophils & 50 & \\
\hline basophils & 20 & \\
\hline Platelets count (per $\mathrm{mm}^{3}$ ) & 193000 & $\begin{array}{l}150000-350 \\
000\end{array}$ \\
\hline Mean corpuscular volume(fl) & 94.4 & $80-100$ \\
\hline Prothrombin time (\%) & 91 & $70-100$ \\
\hline International normalized ratio & 1.07 & \\
\hline $\begin{array}{l}\text { Partial thromboplastin time activated (sec); } \\
\text { P/C }\end{array}$ & $55 / 32$ & \\
\hline Fibrinogen (gr/l) & 5.6 & $2.5-4$ \\
\hline D-dimmers (mcg/l) & 0.8 & 0.5 \\
\hline CRP (mg/l) & 48 & $<5$ \\
\hline Procalcitonin (mcg/l) & 0.66 & $<0.5$ \\
\hline Orosomucoid level (gr/l) & 1.62 & $0.57-1.22$ \\
\hline Haptoglobin $(\mathrm{g} / \mathrm{l})$ & 2.79 & $0.87-2.32$ \\
\hline Transferring $(\mathrm{g} / \mathrm{l})$ & 2.04 & $1.77-2.83$ \\
\hline Beta 2 microglobulin (mg/l) & 10.40 & $1-2$ \\
\hline
\end{tabular}

$\mathrm{gr} / \mathrm{dl}=$ gram per decilitre, $\mathrm{mg} / \mathrm{l}=$ milligram per litre, $\mathrm{mcg}=$ microgram per litre, $\mathrm{P} / \mathrm{C}=$ patient/control 
Table 2 Results of blood chemistry tests

\begin{tabular}{|c|c|c|}
\hline Variable & Patient & Normal range \\
\hline Glucose $(\mathrm{mmol} / \mathrm{l})$ & 7.1 & $3.1-6.4$ \\
\hline $\mathrm{HbA1c}(\%)$ & 6.4 & $<7$ in diabetic patients \\
\hline Urea nitrogen $(\mathrm{mmol} / \mathrm{l})$ & 21.9 & $1.7-8.3$ \\
\hline Creatinine (umol/l) & 501 & $<106$ \\
\hline Calcium (mmo/l) & 2.03 & $2.15-2.55$ \\
\hline Phosphorus (mmol/l) & 1.38 & $0.87-1.45$ \\
\hline Sodium (mmol/l) & 138 & $136-145$ \\
\hline Potassium (mmo/l) & 4.6 & $3.5-5.1$ \\
\hline Chloride (mmol/l) & 99 & $95-105$ \\
\hline Carbon dioxide (mmol/l) & 18 & $23-29$ \\
\hline Total Bilirubin (umol/l) & 10 & $<22$ \\
\hline Alanine aminotranferase & 14 & $<41 \mathrm{UI} / \mathrm{I}$ \\
\hline Aspartate aminotransferase & 46 & $<37 \mathrm{UI} / \mathrm{I}$ \\
\hline Alkaline phosphatise & 902 & $<270 \mathrm{UI} / \mathrm{l}$ \\
\hline Gamma glutamyl transferase & 476 & $<49 \mathrm{UI} / \mathrm{I}$ \\
\hline Lactate dehydrogenase & 417 & $<480 \mathrm{UI} / \mathrm{l}$ \\
\hline Amylase & 173 & $<220 \mathrm{UI} / \mathrm{I}$ \\
\hline Creatine kinase & 113 & $<190 \mathrm{UI} / \mathrm{I}$ \\
\hline Lactic acid (mmol/l) & 0.76 & $<2$ \\
\hline Iron (umol/l) & 16.5 & $10.7-32$ \\
\hline Iron binding capacity(umol/l) & 46 & $45-72$ \\
\hline Transferrin saturation coefficient (\%) & 0.36 & $0.15-40$ \\
\hline Ferritin (ng/ml) & 898.5 & $30-240$ \\
\hline Ammonia (umol/l) & 88 & $16-60$ \\
\hline Plasma osmolarity (moSm/l) & 315 & $275-305$ \\
\hline Uric acid (umol/l) & 276 & $<420$ \\
\hline
\end{tabular}

$\mathrm{Mmol} / \mathrm{l}=\mathrm{millimol}$ per litre, $\mu \mathrm{mol} / \mathrm{I}=$ micromol per litre, $\mathrm{mosm} / \mathrm{l}=$ milliosmol per litre, $\mathrm{ng} / \mathrm{ml}=$ nanogram per millilitre

CSF VDRL cannot exclude it, and FTA-Abs is less specific, but more sensitive. In our case the diagnosis was difficult because of superimposed other diseases which unmasked its latent form by impairing immunity: complicated diabetes mellitus, Chronic HBV infection under anti-viral therapy, end stage renal failure and therapeutic agents prescribed for dialyzed patients. However, the diagnosis of tertiary syphilis has been guided by previous history of contracting sexually HbsAg and the slowly progressive proximal lower limbs weakness, associated with skin eruptions, pneumonitis and cholestatic hepatitis. Uveitis was diagnosed in another hospital without knowing the syphilitic course. Pulmonary involvement in our case filled the criteria proposed by Coleman et al [5], and ceftriaxone therapy was initially given empirically. The decision to continue ceftriaxone over two weeks was based on positive serologic tests. Shan et al [6], described a case of successful treatment of symptomatic neurosyphilis with ceftriaxone, as in ours. Echocardiography finding of calcified bicuspid Aortic valve might be a consequence of either syphilis, or secondary hyperparathyroidism, or both. The neurological signs
Table 3 Results of immunology laboratory tests

\begin{tabular}{|c|c|c|}
\hline Variable & Patient & $\begin{array}{l}\text { Normal } \\
\text { range }\end{array}$ \\
\hline Antinuclear antibody (Abs) & $<1: 80$ & $>1: 80$ \\
\hline Anti DNA Abs & Negative & \\
\hline Rheumatoid factor & Negative & \\
\hline \multicolumn{3}{|l|}{$\begin{array}{l}\text { Antineutrophil cytoplasmic } \\
\text { Abs }\end{array}$} \\
\hline Anti PR3 abs & $<10$ & $<20$ \\
\hline Anti MPO abs & $<10$ & $<20$ \\
\hline \multicolumn{3}{|l|}{ Complement } \\
\hline Total & N/A & \\
\hline $\mathrm{C} 3$ & 1.6 & $0.90-1.73$ \\
\hline C4 & N/A & \\
\hline $\lg G$ & 14.4 & $6.5-12.08$ \\
\hline $\lg A$ & 2.92 & $1-3.20$ \\
\hline $\lg M$ & 0.52 & $0.49-1.38$ \\
\hline Cryoglobulin & NEGATIVE & \\
\hline Anticardiolipin Abs & $<10$ & $<23$ \\
\hline HCV Abs & negative & \\
\hline $\mathrm{HbsAg}$ & positive & \\
\hline HbsAbs & $<5$ & \\
\hline \multicolumn{3}{|l|}{ HbcAbs } \\
\hline $\lg G$ & positive & \\
\hline $\lg M$ & negative & \\
\hline HIV $1 \& 2$ & negative & \\
\hline Thyroid function test & $\begin{array}{l}\text { low T3 with normal } \\
\text { TSH }\end{array}$ & \\
\hline Chlamydia (Ig M) & $<10$ & $<10$ \\
\hline Mycoplasma (lg M) & negative & \\
\hline Legionella urinary Ag & negative & \\
\hline Lyme disease (IgM) & negative & \\
\hline \multicolumn{3}{|c|}{ Plasma protein electrophoresis } \\
\hline Total proteins $(\mathrm{g} / \mathrm{l})$ & 74 & $66-87$ \\
\hline Albumin (g/l) & 37.4 & $36-48$ \\
\hline Alpha $1(g / l)$ & 3 & $1-3$ \\
\hline Alpha $2(g / l)$ & 11.4 & $4-8$ \\
\hline Beta $(g / l)$ & 9.2 & $5-10$ \\
\hline Gamma $(g / l)$ & 12.9 & $7-13$ \\
\hline A/G ratio: & 1.02 & \\
\hline Folic acid level (nmol/l) & 9 & $>7$ \\
\hline B12 vitamin level (pmol) & 477 & $133-675$ \\
\hline
\end{tabular}

Abs $=$ antibodies, $\mathrm{Ag}=$ antigen, $\mathrm{pmol} / \mathrm{l}=$ picomol per litre

and symptoms presented herein might evoke a picture similar to that of chronic myelopathy in which the pyramidal pathway is involved, characterized by active reflexes and positive Babinski's sign. This latter was negative probably due to peripheral polyneuropathy that was not confirmed by either physical examination or on EMG/NCS registering. A combined neuro-muscular syphilitic affection remained the most likely in addition to a painful radiculopathy abolished by pain killers. 
However, we can not exclude syphilitic spinal cord involvement by simple CT scan finding. EL Quessar et al [7], reported a case of spinal cord gumma with normal myelography and Brain CT. We didn't perform lumbar puncture or further explorations due to rapid clinical improvement under ceftriaxone therapy and antiviral drugs have been continued.

\section{Conclusion}

Syphilis remains a great imitator because its signs and symptoms are not pathognomonic when superimposed upon chronic diseases yielding high morbidity. Keeping high grade of suspicion of syphilis in individual who are at risk of other sexually transmitted infection and viceversa is mandatory to limit syphilitic end organ damage. In hemodialyzed patients ceftriaxone is gaining ground when treating acquired syphilis and is equivalent to benzathin penicillin not only because of its practical administration but due to impaired pharmacokinetics of the latter. The rule in treating the sex partner of an infected patient regardless of whether or not infected should be respected as in ours.

\section{Consent}

Written informed consent was obtained from the patient for submission of manuscript for publication of this case. A copy of the consent is available for review by the Editor-in-Chief of this journal.

\section{Abbreviations}

EMG/NCS: electomyogram test/nerve conduction studies; MSGS: muscle straight grading scale; VDRL: venereal disease reference laboratory; TPHA: treponema pallidum haemagglutination assay; FTA abs: florescent treponemal antibody-absorption test; C/S: culture and sensitivity; CXR: chest $\mathrm{x}$-ray; EKG: electrocardiogram; iPTH: intact parathyroid hormone; HBV: hepatitis B virus; HCV: hepatitis C virus.

\section{Acknowledgements}

There is no source of funding for this manuscript.

\section{Author details}

${ }^{1}$ Department of nephrology, CH Louis Jaillon Saint-Claude, 39206, France. ${ }^{2}$ Department emergency and trauma, CH Louis Jaillon Saint-Claude, 39206, France. ${ }^{3}$ Department of Biochemistry and Microbiology, $\mathrm{CH}$ Louis Jaillon, Saint-Claude, 39206, France. ${ }^{4}$ Department of internal medicine, $\mathrm{CH}$ Louis Jaillon Saint-Claude, 39206, France.

\section{Authors' contributions}

All authors contributed to each stage of this work, OD, NT, JPG, SB, FMJ, JS and JD all have: (1) made substantial contributions to conception and design, or acquisition of data, or analysis and interpretation of data; (2) been involved in drafting and revising the manuscript; and (3) given final approval of the version to be published.

\section{Competing interests}

The authors declare that they have no competing interests.

Received: 6 November 2009

Accepted: 13 January 2010 Published: 13 January 2010
References

1. French P: Syphilis Clinical review. BMJ 2007, 334:143-147.

2. Yahyaoui M, Serragui S, Regragui W, Errguig L, Mouti O, Benomar A, Chkili T: Epidemiological and clinical aspects of neurosyphilis in Morocco. East Mediterr Health J 2005, 11(3):470-477.

3. Baughn RE, Musher DM: Secondary syphilitic lesions. Clinical Microbiology reviews 2005, 18(1):205-216.

4. Sabbatani S, Manfredi R, Chiodo F: Neurosyphilis in a young adult: very early tertiary syphilis?. International journal of STD \& AIDS 2005, 16:832-834.

5. Coleman DL, Mcphee SJ, Ross TF, Naughton JL: Naughton Secondary syphilis with pulmonary involvement. West J Med 1983, 138(6):875-877.

6. Shann S, Wilson J: Treatment of neurosyphilis with ceftriaxone Sex. Transm. Infection 2003, 79:415-416.

7. EL Quessar A, EL Hassani R, Jiddane M, Boukhrissi N: Syphilitic spinal cord gumma (French). J Neuroradiol 2000, 27:207-210.

doi:10.1186/1757-1626-3-23

Cite this article as: Dahmani et al:: Progressive painless lower limbs weakness in a dialyzed patient: undiagnosed tertiary syphilis: a case report. Cases Journal 2010 3:23.

\section{Submit your next manuscript to BioMed Central and take full advantage of:}

- Convenient online submission

- Thorough peer review

- No space constraints or color figure charges

- Immediate publication on acceptance

- Inclusion in PubMed, CAS, Scopus and Google Scholar

- Research which is freely available for redistribution

Submit your manuscript at www.biomedcentral.com/submit 